\title{
Stabilization of high-risk plaques
}

\author{
Kohei Takata ${ }^{1}$, Satoshi Imaizumi ${ }^{1}$, Bo Zhang $^{2}$, Shin-ichiro Miura ${ }^{1}$, Keijiro Saku ${ }^{1}$ \\ ${ }^{1}$ Department of Cardiology, ${ }^{2}$ Department of Biochemistry, Fukuoka University School of Medicine, Fukuoka 814-0180, Japan \\ Contributions: (I) Conception and design: K Takata, S Imaizumi; (II) Administrative support: SI Miura, K Saku; (III) Provision of study materials or \\ patients: K Takata, S Imaizumi; (IV) Collection and assembly of data: K Takata, S Imaizumi, B Zhang; (V) Data analysis and interpretation: None; (VI) \\ Manuscript writing: All authors; (VII) Final approval of manuscript: All authors. \\ Correspondence to: Satoshi Imaizumi, MD, PhD. Department of Cardiology, Fukuoka University School of Medicine, 7-45-1 Nanakuma, Jonan-ku, \\ Fukuoka 814-0180, Japan. Email: simaizumi@fukuoka-u.ac.jp.
}

\begin{abstract}
The prevalence of atherosclerotic cardiovascular diseases (ASCVDs) is increasing globally and they have become the leading cause of death in most countries. Numerous experimental and clinical studies have been conducted to identify major risk factors and effective control strategies for ASCVDs. The development of imaging modalities with the ability to determine the plaque composition enables us to further identify high-risk plaque and evaluate the effectiveness of different treatment strategies. While intensive lipid-lowering by statins can stabilize or even regress plaque by various mechanisms, such as the reduction of lipid accumulation in a necrotic lipid core, the reduction of inflammation, and improvement of endothelial function, there are still considerable residual risks that need to be understood. We reviewed important findings regarding plaque vulnerability and some encouraging emerging approaches for plaque stabilization.
\end{abstract}

Keywords: Atherosclerotic cardiovascular diseases (ASCVDs); inflammation; low-density lipoprotein cholesterol (LDL-C); statins; thin-cap fibroatheroma (TCFA)

Submitted Aug 11, 2015. Accepted for publication Oct 19, 2015.

doi: $10.21037 / \mathrm{cdt} .2015 .10 .03$

View this article at: http://dx.doi.org/10.21037/cdt.2015.10.03

\section{Introduction}

According to the World Health Organization (WHO), an estimated 17.5 million people died from atherosclerotic cardiovascular diseases (ASCVDs) in 2012, which represents $31 \%$ of all global deaths. Various risk factors are associated with the increased rate of adverse events and the increased mortality of ASCVDs (1). It has been proven that maintaining a healthy lifestyle, such as by not smoking, maintaining a healthy body mass index, exercise, and a healthy diet, is important for preventing ASCVDs (2). However, people develop numerous risk factors, such as dyslipidemia, diabetes, and hypertension, which contribute to the atherosclerotic plaque burden and lead to ASCVDs. Medical treatments that target ASCVD risk factors have been proven to reduce adverse events and mortality (3).

With respect to reducing mortality, it is especially important to elucidate the mechanisms of atherosclerotic plaque development and to identify approaches to stabilize atherosclerotic plaque, especially "vulnerable plaque".

\section{Pathology of "vulnerable plaque"}

It is difficult to distinguish vulnerable plaque from atherosclerotic lesions in a clinical setting, and this has led to the development of imaging modalities that can detect high-risk atherosclerotic plaques (4). Although coronary angioscopy was developed in the 1980's (5), a morphological approach is insufficient to capture the detailed mechanisms of plaque vulnerability. Therefore, other imaging modalities with the ability to clarify the characteristics of plaque composition have been developed, such as intravascular ultrasound-virtual histology (IVUS$\mathrm{VH}$ ), optical coherence tomography (OCT), and nearinfrared spectroscopy (NIRS).

These imaging modalities and pathological studies 
have demonstrated that acute myocardial infarction (AMI) can be caused by the rupture or erosion of a coronary atherosclerotic plaque $(6,7)$. Atherosclerotic plaque consists of various components, i.e., lipid, calcified lesion, vascular smooth muscle cells (VSMCs), and inflammatory cells (i.e., $\mathrm{T}$ lymphocytes and macrophage cells). While the concept of atherosclerosis is complicated, it has been recognized that the stability of atherosclerotic plaque depends on the relationships among these components. VSMCs synthesize collagen I and III, which are important for plaque stabilization. On the other hand, inflammatory cells release various molecules, including metalloproteinases (MMPs), which lead to plaque instability.

Morphological and pathological studies have demonstrated that infiltrated inflammatory cells and the percentage of the lipid core are associated with positive remodeling (PR), which reflects the vulnerability of a culprit lesion (8). Fibrous-cap atheroma can be divided into a coronary arterial lumen and a lipid or necrotic core, and its thickness reflects plaque stability. Thin-cap fibroatheroma (TCFA), which is a morphological feature of vulnerable plaque, i.e., rupture-prone plaque, is characterized by a large lipid or necrotic core with an overlying fibrous cap measuring $<65 \mu \mathrm{m}$, consisting of rare VSMCs, PR, spotty calcification, and numerous inflammatory cells (9-11). Both the size of the necrotic core and the thickness of TCFA may be structural determinants of vulnerability (12).

Vulnerable plaques by erosion (erosion-prone plaques), which lack surface endothelium, are defined solely by their associated events. Coronary plaque erosion accounts for $40 \%$ of thrombotic coronary sudden deaths (13), and is common in smokers and younger patients, especially premenopausal women (14). VSMCs and proteoglycans are predominant, while inflammatory cells are variable (13-15). The missing endothelium may be associated with vasospasm, and the vessels show negative remodeling $(14,15)$. While the mechanisms of erosion are clearly different from those of plaque rupture, we do not yet know the details.

\section{Targets for plaque stabilization}

\section{LDL cholesterol and cardiovascular events}

It is well known that lowering the low-density lipoprotein cholesterol (LDL-C) level is useful in both the primary and secondary prevention of cardiovascular events (16-18). Statins are the most common therapeutic agents for lipid- lowering (19). The major effect of statins is the reduction of LDL-C levels through the inhibition of 3-hydroxy3-methylglutaryl coenzyme A (HMG-CoA) reductase. Statins have favorable pleiotropic effects on atherosclerosis, including a reduction in lipid volume, anti-inflammatory activity, and improvement of endothelial function (20-22). They are now considered to be essential for treating ASCVDs due to their impact on atherosclerotic plaque. The classical understanding is that the infiltration of LDL-C to the intima is an early step that induces subsequent inflammatory responses in the vessel wall. Statins exert pleiotropic effects to interrupt inflammation within atherosclerotic plaque, which suppresses the secretion of inflammatory mediators (23).

A meta-analysis in 14 randomized clinical trials (RCTs) reported a relationship between achieved LDL-C and major adverse cardiac events (MACE) (24). In this study, there was a $12 \%$ proportional reduction in all-cause mortality per $1.0 \mathrm{mmol} / \mathrm{L}(39 \mathrm{mg} / \mathrm{dL})$ reduction in LDL-C [rate ratio (RR) 0.88 ; 95\% CI, 0.84-0.91], and corresponding reductions in myocardial infarction or coronary death (RR 0.77 ; 95\% CI, 0.74-0.80), in the need for coronary revascularization (RR 0.76 ; 95\% CI, 0.73-0.80), and in fatal or non-fatal stroke (RR 0.83; 95\% CI, 0.78-0.88). The Collaborative Atorvastatin Diabetes (CARDS) study assessed the effectiveness of statin (atorvastatin $10 \mathrm{mg}$ ) therapy for the primary prevention of major cardiovascular events in patients with diabetes mellitus (DM) without high concentrations of LDL-cholesterol. The group allocated to statin was associated with a $37 \%$ reduction in the incidence of major cardiovascular events $(\mathrm{P}=0.001)$ compared to the placebo group. Acute coronary heart disease events were reduced by $36 \%$, coronary revascularization by $31 \%$, and stroke by $48 \%$ (25). Diabetic patients have a high atherosclerotic risk with about a three-fold increased risk of cardiovascular disease (26). This study suggested that statins are also potent in type 2 diabetes even without high concentrations of LDL-cholesterol. The PROVE-IT TIMI 22 (Pravastatin or Atorvastatin Evaluation and Infection Therapy-Thrombolysis in Myocardial Infarction 22) study showed that an achieved LDL-C under $60 \mathrm{mg} / \mathrm{dL}$ was associated with a lower risk of MACE in patients after acute coronary syndrome (ACS). (27) In this study, patients with ACS who were treated with atorvastatin were divided into 5 groups according to four-month LDL-C levels: $>100,>80$ to $100,>60$ to $80,>40$ to 60 , and $<40 \mathrm{mg} / \mathrm{dL}$. Both of the lowest LDL groups, $>40$ to 60 (hazard ratio $0.68 ; 95 \% \mathrm{CI}$, $0.50-0.92$ ) and $<40$ (hazard ratio $0.61 ; 95 \%$ CI, 0.40-0.91), 


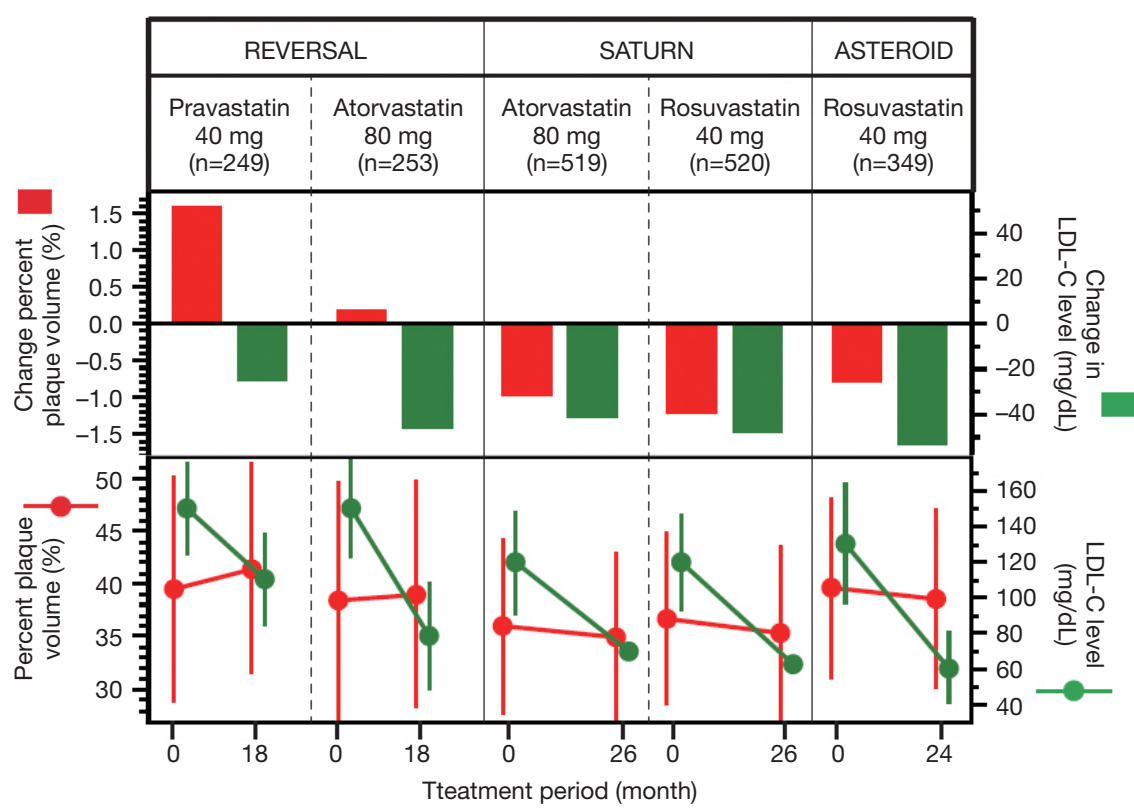

Figure 1 IVUS studies examining the impact of statin therapy on plaque progression/regression. The REVERSAL (Reversal of Atherosclerosis with Aggressive Lipid Lowering) (32) study compared the efficacy of two statin regiments of different lipid lowering intensities on coronary atherosclerosis. The SATURN (34) (Effect of Rosuvastatin versus Atorvastatin) study compared the efficacy of two intensive statin regiments on coronary atherosclerosis. The ASTEROID (28) (A Study to Evaluate the Effect of Rosuvastatin on Intravascular Ultrasound-Derived Coronary Atheroma Burden) study was the first large-scale IVUS study to evaluate the effect of intensive statin therapy on coronary atherosclerosis. LDL-C, low-density lipoprotein cholesterol; IVUS, intravascular ultrasound.

showed significantly lower endpoint rates than the reference group (>80 to 100$)$.

\section{Reduction of $L D L$ cholesterol and modification of plaque instability}

Various imaging modalities have been used to elucidate the mechanism underlying these relationships, and have demonstrated that statin therapies attenuate plaque progression and strengthen plaque stability. Various studies using IVUS have demonstrated that lipid-lowering therapy with statins can achieve plaque regression (28). The ESTABLISH (Demonstration of the Beneficial Effect on Atherosclerotic Lesions by Serial Volumetric Intravascular Ultrasound Analysis During Half a Year After Coronary Event) study clarified for the first time that statin (atorvastatin $20 \mathrm{mg}$ daily) significantly reduced plaque volume consistent with a reduction in the LDL-C level (29). The PROSPECT (30) (Providing Regional Observations to Study Predictors of Events in the Coronary Tree) and VIVA (31) (VH-IVUS in vulnerable atherosclerosis) studies showed that the coronary plaque burden was closely related to MACE risk. Furthermore, the optimal level of LDL-C has been sought, i.e., high-intensity statin therapy (HIST) $v s$. low-intensity statin treatment (LIST) $(28,32,33)$. In the REVERSAL (Reversal of Atherosclerosis with Aggressive Lipid Lowering) study, patients were randomly assigned to receive a moderate lipid-lowering regimen $(40 \mathrm{mg}$ of pravastatin) or an intensive lipid-lowering regimen $(80 \mathrm{mg}$ of atorvastatin) for 18 months. The primary efficacy parameter was the percentage change in atheroma volume as analyzed by IVUS. Although the coronary atherosclerosis progressed in the pravastatin group, progression did not occur in the atorvastatin group. As a result, the progression rate was significantly lower in the atorvastatin (intensive) group, which suggested that HIST is superior to LIST for slowing plaque progression (Figure 1).

A lot of studies have reported that statin therapies have favorable effects on the coronary plaque composition. Some studies used coronary angioscopy, with which the lipid core can be seen through TCFA, but not through a thicker fibrous cap. Takano et al. first reported in 2003 using angioscopy that the administration of atorvastatin for 12 months improved the yellow grade of coronary plaques, 
which is associated with vulnerability to disruption. There was a strong correlation between the changes in LDL-C levels and the changes in the mean yellow score $(r=0.81$, $\mathrm{P}<0.0001$ ) (35). Recently, color fluorescent angioscopy has become available as an advanced modality. It can be used to visualize not only collagen fibers but also oxidized LDL, and can provide useful information related to the plaque composition (36).

Among the reports with IVUS, Taguchi et al. reported that early statin therapy reduced the necrotic core component in patients with ACS, even in the case of plaque progression (37). A study with rosuvastatin (low dose: $5 \mathrm{mg} /$ day, high dose: $40 \mathrm{mg} /$ day) in patients with STsegment elevation myocardial infarction (STEMI) clarified that the necrotic core component was reduced only in the

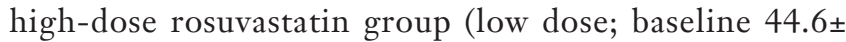
$38.2 \mathrm{~mm}^{3}$, 12-month follow-up $41.2 \pm 40.3 \mathrm{~mm}^{3}, \mathrm{P}<0.29$ $v s$. high dose; baseline $47.4 \pm 38.2 \mathrm{~mm}^{3}, 12$-month followup $40.7 \pm 34.4 \mathrm{~mm}^{3}, \mathrm{P}=0.003$ ) (38). Another study that used VH-IVUS in patients with stable angina pectoris (AP) demonstrated that one year of lipid-lowering therapy with fluvastatin reduced the fibro-fatty volume (baseline $80.1 \pm 57.9 \mathrm{~mm}^{3}$ vs. follow-up $\left.32.5 \pm 27.7 \mathrm{~mm}^{3}, \mathrm{P}<0.0001\right)$ and increased the fibrous tissue volume (baseline 146.5 \pm $85.6 \mathrm{~mm}^{3}$ vs. follow-up $\left.163.3 \pm 94.5 \mathrm{~mm}^{3}, \mathrm{P}<0.0001\right)$. In addition, this study showed a positive correlation between the changes in LDL-C levels and the changes in the fibrofatty volume $(\mathrm{R}=0.703, \mathrm{P}<0.0001)$ (39). The TRUTH (Treatment With Statin on Atheroma Regression Evaluated by Intravascular Ultrasound With Virtual Histology) study also demonstrated that statin therapies in patients with stable and unstable AP not only reduced the fibrofatty volume at 8 months (pitavastatin $4 \mathrm{mg} /$ day; baseline $1.09 \mathrm{~mm}^{3} / \mathrm{mm}$, follow-up $0.81 \mathrm{~mm}^{3} / \mathrm{mm}, \mathrm{P}=0.001$, pravastatin $20 \mathrm{mg} /$ day; baseline $1.05 \mathrm{~mm}^{3} / \mathrm{mm}$, follow-up $\left.0.83 \mathrm{~mm}^{3} / \mathrm{mm}, \mathrm{P}=0.0008\right)$ but also increased the calcium volume (pitavastatin $4 \mathrm{mg} /$ day; baseline $0.42 \mathrm{~mm}^{3} / \mathrm{mm}$, follow-up $0.55 \mathrm{~mm}^{3} / \mathrm{mm}, \mathrm{P}=0.001$, pravastatin $20 \mathrm{mg} /$ day; baseline $0.44 \mathrm{~mm}^{3} / \mathrm{mm}$, follow-up $0.55 \mathrm{~mm}^{3} / \mathrm{mm}$, $\mathrm{P}=0.005$ ) (40). Recently, a post-hoc analysis of 8 prospective randomized trials using IVUS revealed that statins promote calcification in coronary plaques, and the changes in the formation of calcification were independent of LDL-C and CRP (41). These effects of statins on coronary calcification may reduce the vulnerability of coronary plaques.

Some studies using OCT demonstrated that the fibrouscap tended to thicken in response to HIST $(42,43)$. In addition, the increase in fibrous cap thickness achieved with a HIST was significantly correlated with the reduction of infiltrated macrophages, LDL-C, oxidized LDL, high-sensitivity $\mathrm{C}$-reactive protein (CRP), and matrix metalloproteinase-9 (MMP-9) (44). As described above, it has been demonstrated that statin therapies stabilize plaque by converting its components.

Ezetimibe reduces the absorption of cholesterol from the intestine by inhibiting the Niemann-Pick C1-like 1 (NPC1L1) protein and serves as another LDL-C-lowering agent (45). Recently, it was reported that ezetimibe helps to improve cardiovascular outcomes (46). The LDL-C level could be reduced by an additional $23 \%$ to $24 \%$ by the addition of ezetimibe to statins (46-48). With regard to its effect on plaque composition, it has been shown that ezetimibe, when added to fluvastatin, increased the fibrous cap thickness and reduced lipid plaque (49).

Despite these impressive cardioprotective effects of lowering the LDL-C level, the residual risk is still very important. Statins can reduce cardiovascular events by no more than 40\% (50). In the SATURN (34) (Effect of Rosuvastatin versus Atorvastatin) and ASTEROID (28) (A Study to Evaluate the Effect of Rosuvastatin on Intravascular Ultrasound-Derived Coronary Atheroma Burden) studies, coronary plaques progressed in approximately $30 \%$ of patients despite low LDL-C levels. This residual risk is related to the presence of small dense LDL, triglyceride, low levels of high-density lipoprotein cholesterol (HDL-C) and DM.

\section{High-density lipoprotein (HDL)}

Various epidemiological studies have revealed that HDL-C levels are inversely related to the risk of ASCVDs (51-54). In the Framingham Heart Study, a low level of HDL-C was shown to be a predictor of coronary heart disease, independent of LDL-C levels (55). The treating to new targets (TNT) study demonstrated that a low HDL-C level remains a good predictor of MACE even when an LDL-C level of under $70 \mathrm{mg} / \mathrm{dL}$ has been achieved with statins (56). Thus, a low level of HDL-C is recognized as a strong and independent risk factor for ASCVDs (57). This favorable effect of HDL-C is thought to be attributable to several atheroprotective effects of HDL (58). A classical interpretation is that HDL promotes the transport of excess cholesterol from macrophage cells in peripheral tissues to the liver (i.e., cholesterol efflux capacity). In addition, HDL has anti-oxidant, anti-inflammatory, anti-thrombotic or fibrinolytic activities, and improves endothelial function 
by activating endothelial nitric oxide (NO) synthase. Based on these anti-atherosclerotic activities, HDL-C-targeted therapies have been advocated.

With regard to coronary atherosclerosis, it has been demonstrated in a pool analysis of 1,455 patients using IVUS that raising HDL-C levels by more than $7.5 \%$ was associated with plaque regression in patients who achieved LDL-C under $87.5 \mathrm{mg} / \mathrm{dL}$ with statins (59). Furthermore, another study of 261 consecutive ACS patients reported that the HDL-C level was positively associated with fibrous-cap thickness. They suggested that HDL-C has potential to be a beneficial therapeutic target for plaque stabilization (60).

However, these past studies failed to show an association between an increase in the HDL-C level and a reduction in the risk of ASCVDs $(61,62)$. In the AIM-HIGH trial, there was no clinical benefit in patients with ASCVD with the addition of niacin to statin therapy, despite significant increases in HDL cholesterol levels (from 35 to $42 \mathrm{mg} / \mathrm{dL}$ ) and decreases in triglyceride levels (from 164 to $122 \mathrm{mg} / \mathrm{dL}$ ) (63). Addition of the cholesterol ester transfer protein (CETP) inhibitor dalcetrapib increased HDL cholesterol levels from baseline by $31 \%$ to $40 \%$ in patients with ACS, but did not have significant effect on major cardiovascular outcomes including the rates of myocardial infarction and death from coronary heart disease (64).

As a result, the quality of HDL, or HDL function, rather than its quantity, has lately been the focus of increasing attention. Khera et al. reported that the cholesterol efflux capacity of HDL was strongly and inversely associated with the likelihood of angiographic coronary disease, independent of the HDL cholesterol level (65). In addition, the cholesterol efflux capacity of HDL has been shown to be inversely associated with the incidence of cardiovascular events (66).

Apolipoprotein A-I (apoA-I), which contains 243 amino acids and is a major component protein of HDL, plays important roles in HDL function. Various basic studies have been performed using recombinant HDL [apoA-I Milano (67), CER-001 (68)], apoA-I mimetic peptides (69), reconstituted HDL [rHDL (70), CSL111 (71)], delipidated HDL (72), and antagonist of microRNA-33 (Anti-miR33) (73). ApoA-I mimetic peptides are a major example; the $5 \mathrm{~F}$ peptide inhibits the formation of aortic plaque in mice receiving a high-fat diet, which is the first in vivo demonstration that apoA-I mimetic peptides have atheroprotective properties (74). An ApoA-I mimetic peptide that contains 24 amino acids without phospholipids, Fukuoka University ApoA-I Mimetic
Peptide (FAMP), enhanced HDL function and suppressed aortic plaque formation in apoE $\mathrm{KO}$ mice (75). In human studies, intravenous administration of ETC-216 (an apoA-I Milano/1-palmitoyl-2-oleoyl phosphatidylcholine complex) was associated with the significant regression of coronary atherosclerotic plaques as measured by IVUS (76). After the infusion of ETC-216, coronary plaque regression was accompanied by reverse remodeling of external elastic membrane (EEM) without changes in luminal dimensions (77). On the other hand, the ERASE (Effect of reconstituted HDL on Atherosclerosis-Safety and Efficacy) study, which used CSL-111 (reconstituted HDL consisting of apoA-I from human plasma combined with soybean phosphatidylcholine), resulted in no significant reductions in the percentage change in both plaque and atheroma volume, but significantly improved plaque characterization indexes on IVUS and coronary stenosis scores on quantitative coronary angiography (QCA) (78). Moreover, autologous delipidated HDL plasma treatment for ACS patients reduced the changes in total atheroma volume from baseline as analyzed by IVUS (delipidated group vs. control group, $-12.2 \pm 36.8 v s .2 .8 \pm 21.3 \mathrm{~mm}^{3}$ ). Plasma-selective delipidation converted the levels of pre $\beta$ like HDL and $\alpha$-HDL from $5.6 \%$ to $79.1 \%$ and $92.8 \%$ to $20.9 \%$, respectively. These changes in HDL subfraction may be a key point in support of the favorable effects of delipidated HDL. The level of pre $\beta-H D L$, which is the primary acceptor of cholesterol efflux by the ABCA1 transporter, is positively associated with efflux capacity in vitro. Among various HDL functions, efflux capacity and anti-inflammatory activities in particular may have potential to play crucial roles in stabilizing coronary plaques. The potential of these new approaches based on HDL-targeted therapies is substantial, and the results of human studies are eagerly awaited.

\section{Diabetes mellitus (DM)}

DM is associated with a higher morbidity of ASCVDs (79-81). Along with other clinical trials $(26,82,83)$, the Copenhagen City Heart Study showed that the relative risk of the incidence of myocardial infarction in DM was 2- to 3 -fold greater than that in non-DM, independent of the presence of other established risk factors (84). IVUS studies showed that DM accelerated the development of coronary atherosclerosis (85). Coronary specimens from patients with DM contained larger lipid-rich atheroma, infiltrated macrophages, and thrombosis than those from non-DM 
patients (86).

Even in the absence of DM, higher blood glucose levels, higher hemoglobin A1c levels, and insulin resistance (IR) have been shown to be associated with an increased risk of ASCVDs (87-89). IR plays crucial roles in atherosclerosis (90), and it has been clarified that IR was positively associated with coronary severity (91), the coronary calcium score (92), and a remodeling index (93). Various past studies in basic research have supported the results of these clinical trials. They have also linked not only diabetes $(94,95)$ but also glucose tolerance $(96,97)$ to endothelial dysfunction, which is the initial step in the development of atherosclerotic plaque.

Metformin and thiazolidinediones (TZDs) are wellknown to improve IR. The UK Prospective Diabetes Study (UKPDS) Group showed that metformin was superior to diet, sulfonylurea, and insulin with respect to survival benefit and cardiovascular protection (98). Although there is some evidence to support the use of metformin in basic science (99) and some retrospective analyses have indicated that metformin reduced cardiovascular-related morbidity and mortality in type 2 diabetes (100), there is no solid evidence to support the use of metformin for ASCVDs (101). Further randomized, double-blind clinical trials on metformin will be needed in the future.

TZDs are ligands for peroxisome proliferative-activated receptor- $\gamma(\operatorname{PPAR} \gamma)$, which mainly resides in adipose tissue and ameliorates insulin sensitivity. This improvement in insulin sensitivity by TZDs leads to the reduction of blood glucose levels and hemoglobin A1c levels, suppresses inflammation, lowers blood pressure, and decreases urinary proteins $(102,103)$. The PROactive (PROspective pioglitAzone Clinical Trial In macroVascular Events) study failed to prove that pioglitazone had a beneficial effect on the primary endpoint, i.e., the reduction of coronary and peripheral events. Nevertheless, the risk-reduction effect for the secondary endpoint, which was a composite of death, non-fatal myocardial infarction, and stroke, was significantly less than that with the placebo (104). In addition, the PERISCOPE (Pioglitazone Effect on Regression of Intravascular Sonographic Coronary Obstruction Prospective Evaluation) trial reported that pioglitazone showed a significantly slower progression of coronary atherosclerotic plaques compared with glimepiride (105).

Hyperglycemia induces endothelial dysfunction via various mechanisms. After glucose molecules enter the vascular wall, hyperglycemia increases the expression of adhesion molecules, and produces less NO. NO plays key roles in vasodilation and the regulation of platelet activation. Moreover, hyperglycemia induces protein kinase C (PKC) activation, increases the formation of advanced glycation end-products (AGEs) (106), and produces reactive oxygen species (ROS) (107). Raising the intracellular glucose level increases the expression of glycoprotein $\mathrm{Ib}(\mathrm{GpIb})$, which is a mediator of platelet aggression (108). Furthermore, it was reported that insulin activated plasminogen activator inhibitor type 1 (PAI-1) (109).

Postprandial hyperglycemia has been established as a better predictor of cardiovascular events than fasting hyperglycemia $(110,111)$. Postprandial hyperglycemia induces oxidative stress, which leads to inflammation and endothelial dysfunction (112). $\alpha$-glucosidase inhibitors $(\alpha-\mathrm{GIs})$, which delays carbohydrate digestion in the small intestine, have potential to prevent a glucose spike (the difference between the fasting glucose level and the peak level of postprandial hyperglycemia). In fact, both the STOP-NIDDM (Study to Prevent Non-Insulin-Dependent Diabetes Mellitus) trial (113) and a MeRIA (Meta-analysis of Risk Improvement under Acarbose) study (114) reported that $\alpha$-GI acarbose could prevent future cardiovascular events.

Whereas the avoidance of hyperglycemia seems to be important for reducing cardiovascular events, recent clinical trials of intensive glucose-lowering in DM, the ACCORD (Action to Control Cardiovascular Risk in Diabetes) study, the ADVANCE (Action in Diabetes and Vascular Disease: Preterax and Diamicron Modified Release Controlled Evaluation) study and the VADT (Veterans Affairs Diabetes Trial) study, failed to demonstrate a reduction in cardiovascular events (115). An increased rate of hypoglycemia was considered to be one of the factors behind the excess mortality $(116,117)$. Hypoglycemia induces increases in the amount of proinflammatory mediators and platelet activation (118), and this is mainly mediated by the sympathoadrenal system. In addition, hypoglycemia also induces endothelial dysfunction via the production of mitochondrial superoxide (119).

Based on these perspectives, the mean amplitude of glycemic excursion (MAGE) and glycemic variability (GV) have attracted considerable attention. GV has potential to more effectively trigger oxidative stress than chronic sustained hyperglycemia (120). It has also been advocated that $\mathrm{GV}$ may be associated with diabetic complications including cardiovascular events (121). It has been shown that $\mathrm{GV}$ derived from a continuous glucose monitoring system (CGMS) is an independent predictor of MACE in 
AMI with type 2 diabetes (odds ratio 1.592; 95\% CI, 1.034 2.451) (122). In addition, another group demonstrated that MAGE in a plaque-rupture group was significantly higher than that in a non-rupture group (123). Recently, it was clarified that glucose fluctuation may affect the formation of lipid-rich plaques and thinning of the fibrous cap in patients with optimal lipid treatment. The study population consisted of $85 \%$ patients with glucose metabolism disorder. In this study, MAGE was the only independent predictor of the presence of TCFA (124). Thus, it may be important to consider MAGE in the treatment of DM by using diabetic agents, such as $\alpha$-GIs, TZDs, metformin, and incretins, which do not induce hypoglycemia except when administered in combination with sulfonylureas and insulin.

\section{Hypertension}

Blood pressure has been shown to be a strong predictor of cardiovascular deaths $(125,126)$. In fact, it was demonstrated that an increase in systolic and diastolic blood pressure of $20 / 10 \mathrm{mmHg}$ doubles the risk for cardiovascular disease (127). It is also well known that hypertension increases atherosclerotic plaques $(128,129)$. The reduction of blood pressure through lifestyle modification and/ or blood pressure-lowering agents dramatically reduced the risk of ASCVDs (130-132). Consequently various therapeutic agents for lowering blood pressure have been developed, i.e., angiotensin-converting enzyme inhibitors (ACE-Is), angiotensin II receptor blockers (ARBs), $\beta$-blockers, and calcium channel blockers (CCBs).

Activation of the renin-angiotensin system (RAS) plays important roles in cardiovascular events (133). In fact, the HOPE (Heart Outcomes Prevention Evaluation) study showed clinically that RAS inhibition not only lowers blood pressure but is also vasoprotective (134). In this study, the ACE-I ramipril significantly reduced the rates of death (relative risk 0.74; 95\% CI, 0.64-0.87 compared with the placebo group), myocardial infarction (relative risk $0.80 ; 95 \%$ CI, 0.70-0.90), and stroke (relative risk 0.68; $95 \%$ CI, $0.56-0.84)$ in high-risk patients ( $\geq 55$ years old who had evidence of vascular disease or diabetes plus one other cardiovascular risk factor) without evidence of left ventricular systolic dysfunction or heart failure. Similarly, the EUROPA (European trial On reduction of cardiac events with Perindopril in stable coronary Artery disease) study showed that blood pressure-lowering by $5 \mathrm{mmHg}$ with perindopril reduced the cardiovascular risk by $20 \%$ among patients with stable angina without apparent heart failure (135).

There is a connection between the activation of RAS and the formation of thrombus, e.g., angiotensin II (Ang II) activates PAI-1 in ECs (136). The pleiotropic effects of ACE-Is on platelet aggregation have been reported in a clinical study (137). The inhibition of RAS by ACEIs and ARBs leads to a reduction in ROS, suppression of the activation of redox-sensitive pro-inflammatory transcription factors, and the maintenance of $\mathrm{NO}$ production in endothelial cells (ECs) (138). The reduction of free radicals by the inhibition of xanthine oxidase and the reduction of LDL oxidation by ACE-Is brings about plaque stabilization (139). In a rabbit plaque model, ACE-Is and ARBs increased collagen content, VSMCs, and the thickness of TCFA (140). Clinical studies have shown that coronary atherosclerotic plaque volume, as measured by IVUS, significantly decreased after ARB treatment (141-143). ARBs have potential to decrease inflammatory infiltration, increase collagen content and stabilize human carotid plaques (144). Another favorable effect of ARBs beyond their ability to lower blood pressure is the prevention of blood vessel aging by suppressing the senescence of ECs and VSMCs (145-147). In these ways, ACE-Is and ARBs, which block activation of the RAS, may confer a cardioprotective effect beyond their ability to lower blood pressure.

There is abundant evidence on the relation between CCBs and cerebrovascular diseases (148). The PREVENT (Prospective Randomized Evaluation of the Vascular Effects of Norvasc Trial) showed that a long-acting CCB significantly regressed carotid arteriosclerosis. Another important finding of this trial was that amlodipine reduced the rates of unstable angina and coronary revascularization (149). The CAPARES (Coronary Angioplasty Amlodipine Restenosis Study) also showed a reduction of coronary revascularization (150). The vasorelaxant effect of CCBs, i.e., the regulation of $\mathrm{NO}$ production, prevents the formation of abnormal vasoconstrictions, which can lead to plaque rupture. Several atheroprotective effects of amlodipine may also contribute to these results. It has the capacity to inhibit lipid oxidative modification $(151,152)$, and subsequently inflammatory responses (153).

$\beta$-blockers have been used as therapeutic drugs for hypertension for more than 50 years (154). Their efficacies in congestive heart failure and angina have been well established. $\beta$-blockers are particularly effective for preventing recurrent ASCVD events in patients with ACS (130). Some $\beta$-blockers also have the ability to block 
the oxidation of LDL, which leads to foam cell formation and the augmentation of atherosclerotic plaque (155). However, their association with plaque stability is not clear. Further research on the relationship between $\beta$-blockers and coronary atherosclerotic plaque stability will be required.

\section{Smoking}

Cigarette smoking increases the risk of AMI more than that of stable angina (156). Active and passive smoking are strong risk factors for AMI (157). It has been demonstrated that plaque in smokers contains higher levels of extracellular lipid (158). Eroded plaque was associated with smoking, especially in women, compared with ruptured plaque (159). The mechanisms by which smoking promotes atherosclerotic lesions or erosion are not completely elucidated.

Smoking is associated with endothelial dysfunction (160), which is restored by smoking cessation. Toxic gas-phase substances in tobacco damage vascular endothelium due to their proinflammatory effects. Smoking elevates the expression of soluble adhesion molecules, vascular cell adhesion molecule 1 (VCAM-1) and intercellular adhesion molecule 1 (ICAM-1) in ECs. Exposure to cigarette smoke increased intraplaque inflammation and neovascularization, which leads to intraplaque hemorrhage and consequent necrotic core formation (160). Nicotine affects serum thromboxanes A2/B2 and catecholamines, which enhance platelet activation (12). Cigarette smoke extracts decreased prolyl-4-hydroxylase $(\mathrm{P} 4 \mathrm{H})$ expression, which is essential for the folding of newly synthesized collagen polypeptide chains into triple-helical molecules, in ECs and smooth muscle cells, which leads to decreased vascular collagen production (161). Basic research clarified that smokinginduced oxidative stress and inflammation have potential to increase MMP gene expression (162). In fact, smoking was shown to increase MMPs in patients with AMI (163).

With regard to lipids, it is well known that smoking increases the level of LDL-C (164). Nevertheless, a metaanalysis reported that there was no significant change in LDL-C after smoking cessation (165). It was reported that smoking cessation leads to improved HDL functionality (efflux capacity and anti-inflammatory property) (166).

These mechanisms may contribute to the plaque instability and thinning of the fibrous cap by smoking, and to stabilized plaque after smoking cessation. The cessation of smoking, such as with an anti-tobacco program, can lead to the reduction of the risk of tobacco-related ASCVDs events, especially in AMI.

\section{Inflammation}

The relationship between atherosclerosis and inflammation has been well established (167). The REVERSAL trial showed a $36.4 \%$ reduction in CRP in the atorvastatin group compared with a $5.2 \%$ reduction in the pravastatin group, which was an independent predictor of a reduction in plaque progression (32). The SATURN study demonstrated that, after 24 months of statin therapy, non-increasing levels of CRP were independently associated with greater percent atheroma volume regression, and the on-treatment CRP level was significantly associated with MACE (168). The JUPITER (Justification for the Use of Statin in Prevention: An Intervention Trial Evaluating Rosuvastatin) trial showed that statin therapy is effective at preventing cardiovascular events in healthy persons without hyperlipidemia but with elevated levels of high-sensitivity CRP. This trial was stopped early after a median follow-up of 1.9 years since there was a $44 \%$ reduction in the primary endpoint of all vascular events, a $54 \%$ reduction in myocardial infarction, and a $48 \%$ reduction in stroke in the rosuvastatin group compared with the placebo (169).

The responses that serve to protect us against inflammation are called immunity, and these consist of natural and adaptive immunities. $T$ cells play a particularly important role in adaptive immunity, and are considered to be highly involved in the process of atherosclerosis (170). It is well known that $\mathrm{CD}^{+} \mathrm{T}$ helper $(\mathrm{Th})$ cells can differentiate into some distinct subsets, i.e., Th type 1 (Th 1 ), Th type 2 (Th 2), Th type 17 (Th 17), and T regulatory cells (Tregs), which can be distinguished from one another by their cytokine profiles (171). Th 1 produces interferon (INF)- $\gamma$, interleukin (IL)-2, and IL-12. Th 2 produces IL-4, IL-5, IL-10, and IL-13. Th 17 produces IL-17 and IL-22. Tregs can suppress inflammatory responses by various mechanisms.

Each of these subsets plays different roles, and it has been reported that the Th cell-mediated immune response is related to the development of atherosclerotic plaque. Th $1 /$ Tregs have proatherogenic/atheroprotective effects. Th 1 cells play roles in the activation of macrophages, neutrophils, and cytotoxic T lymphocytes. Th 1 cells are related to atherosclerosis, rheumatoid arthritis (172), type $1 \mathrm{DM}(173,174)$, multiple sclerosis, and graft-versushost disease (GVHD) (175). As for atherosclerosis, the presence of Th 1 in human atherosclerotic plaque and a 
positive relationship between Th 1 activity and coronary artery disease have been reported (176). Oxidized LDL, LDL, and heat shock protein 60 (HSP60) activated Th 1 in atherosclerotic plaque as the relevant activating antigen (177-179). In an atherogenic state, Th 1 produces large amounts of INF-r, resulting in the overexpression of MMPs, the reduction of collagen production, and thinning of the fibrous-cap $(180,181)$. In contrast to Th 1 , Tregs can suppress inflammatory responses by various mechanisms (182-186). Tregs serve to maintain immunological tolerance and suppress effector $T$ cell responses (187). The atheroprotective effect of Tregs on atherosclerosis has been reported in both a mouse model and a human study $(188,189)$.

The roles of Th 2 and Th 17 are not completely understood. Th 2 has a stimulatory effect on antibody production and promotes the neutralization of microbes and toxins. It has been considered to be predominant in abdominal aortic aneurysm (190) and allergic diseases $(191,192)$. The effect of Th 2 on atherosclerosis is controversial, since, while IL-5 and IL-13 show atheroprotective effects $(193,194)$, IL-4 may promote atherosclerosis $(195,196)$. As for IL-17, a study on specimens of human atherosclerotic plaque revealed that IL-17 promoted plaque vulnerability (197). However, it has also been reported that a deficiency of IL-17 could result in vulnerable plaque by reducing collagen and VSMCs. Similar unclear results have been reported in other studies (198-202). Further studies are needed to elucidate the roles of IL-17 in atherosclerosis.

Accumulating evidence suggests that it might be possible that the balance of Th cells is important, i.e., a Th $1 / \mathrm{Th} 2$ imbalance may result in atherosclerosis (203). For instance, it has been reported that Th 1 is predominant in ACS $(204,205)$ and unstable angina pectoris (206-208). Similarly, a Th 17/Tregs imbalance has been associated with plaque destabilization and its progression (209,210).

As described above, statins are widely used for the reduction of LDL-C and plaque stabilization. They are also useful with respect to the relationship between inflammation and Th cells. Statins may mainly suppress Th1 activity in the acute phase of ACS. After the administration of rosuvastatin, there was a reduction in the pro-inflammatory cytokines that are related to Th 1 (INF- $\gamma)$. On the other hand, there was no change in the anti-inflammatory cytokines that are related to Th 2 (IL-4 and IL-10) (211). It has been reported that statins promote the differentiation of Tregs (212), and restrain the differentiation of Th 17 (213). Kruppel-like factor 2 (KLF2), which regulates the expression of molecules essential for naive $T$ cell recirculation and the maintenance of $T$ cell quiescence, plays a key role in this mechanism (214).

HDL also has potential to suppress the immune response of Th 1 and Th 17 by modulating dendritic cell maturation and function (215). On the other hand, an inverse relationship has been reported between Tregs and the HDL-C level (216). Further studies are needed to elucidate the role of HDL in atherosclerosis.

\section{Conclusions}

A growing body of evidence indicates that plaque progression can be suppressed or even reversed by antiatherosclerotic medications, especially statins. Currently, the plaque burden and composition, which can be elucidated by various imaging modalities, are the main targets for medical treatment. We are assessing the effects of antiatherosclerotic medications not only in terms of the event rate but also using these imaging modalities. However, it is possible that these modalities evaluate only part of the plaque morphology, pathology, and cardiovascular outcome. The mechanisms of plaque vulnerability are not fully elucidated, and various projects are ongoing in not only basic research but also clinically. One of the important topics clinically is the arrival of proprotein convertase subtilisin/kexin type 9 (PCSK-9) inhibitors, which reduce LDL-C levels $>50 \%$ in combination with statins, and which may have potential as an anti-atherosclerotic treatment, especially for high-risk patients. Ongoing and further studies should help to determine the most effective approach to stabilize atherosclerotic plaque and improve the cardiovascular outcome.

\section{Acknowledgements}

None.

\section{Footnote}

Conflicts of Interest: KS had research and education grants, consulting, and promotional speaking fees from MSD Co., Pfizer Co. Ltd., Novartis, Takeda Pharmaceutical Co., Ltd., Bayer, and Eli Lilly, Co. (clinical research grant), Japan. SM had promotional speaking fees from Takeda Pharmaceutical Co., Ltd., Japan. KS and SM are Directors of NPO Clinical and Applied Science, Fukuoka, Japan. KS has an Endowed 
Department of Molecular Cardiovascular Therapeutics, Fukuoka University, which is supported by MSD Co., Ltd. SM is a member of Department of Molecular Cardiovascular Therapeutics. The other authors have no conflicts of interest to declare.

\section{References}

1. Morris PB, Ballantyne CM, Birtcher KK, et al. Review of clinical practice guidelines for the management of LDLrelated risk. J Am Coll Cardiol 2014;64:196-206.

2. Chomistek AK, Chiuve SE, Eliassen AH, et al. Healthy lifestyle in the primordial prevention of cardiovascular disease among young women. J Am Coll Cardiol 2015;65:43-51.

3. Go AS, Mozaffarian D, Roger VL, et al. Heart disease and stroke statistics--2013 update: a report from the American Heart Association. Circulation 2013;127:e6-e245.

4. Fleg JL, Stone GW, Fayad ZA, et al. Detection of highrisk atherosclerotic plaque: report of the NHLBI Working Group on current status and future directions. JACC Cardiovasc Imaging 2012;5:941-55.

5. Spears JR, Marais HJ, Serur J, et al. In vivo coronary angioscopy. J Am Coll Cardiol 1983;1:1311-4.

6. Akasaka T, Kubo T, Mizukoshi M, et al. Pathophysiology of acute coronary syndrome assessed by optical coherence tomography. J Cardiol 2010;56:8-14.

7. Finn AV, Nakano M, Narula J, et al. Concept of vulnerable/unstable plaque. Arterioscler Thromb Vasc Biol 2010;30:1282-92.

8. Varnava AM, Mills PG, Davies MJ. Relationship between coronary artery remodeling and plaque vulnerability. Circulation 2002;105:939-43.

9. Virmani R, Burke AP, Farb A, et al. Pathology of the vulnerable plaque. J Am Coll Cardiol 2006;47:C13-8.

10. Kolodgie FD, Burke AP, Farb A, et al. The thin-cap fibroatheroma: a type of vulnerable plaque: the major precursor lesion to acute coronary syndromes. Curr Opin Cardiol 2001;16:285-92.

11. Kataoka Y, Puri R, Hammadah M, et al. Spotty calcification and plaque vulnerability in vivo: frequencydomain optical coherence tomography analysis. Cardiovasc Diagn Ther 2014;4:460-9.

12. Ylä-Herttuala S, Bentzon JF, Daemen M, et al. Stabilisation of atherosclerotic plaques. Position paper of the European Society of Cardiology (ESC) Working Group on atherosclerosis and vascular biology. Thromb Haemost 2011;106:1-19.
13. Farb A, Burke AP, Tang AL, et al. Coronary plaque erosion without rupture into a lipid core. A frequent cause of coronary thrombosis in sudden coronary death. Circulation 1996;93:1354-63.

14. Virmani R, Kolodgie FD, Burke AP, et al. Lessons from sudden coronary death: a comprehensive morphological classification scheme for atherosclerotic lesions. Arterioscler Thromb Vasc Biol 2000;20:1262-75.

15. Falk E, Nakano M, Bentzon JF, et al. Update on acute coronary syndromes: the pathologists' view. Eur Heart J 2013;34:719-28.

16. Heart Protection Study Collaborative Group. MRC/ BHF Heart Protection Study of cholesterol lowering with simvastatin in 20,536 high-risk individuals: a randomised placebo-controlled trial. Lancet 2002;360:7-22.

17. Sacks FM, Pfeffer MA, Moye LA, et al. The effect of pravastatin on coronary events after myocardial infarction in patients with average cholesterol levels. Cholesterol and Recurrent Events Trial investigators. N Engl J Med 1996;335:1001-9.

18. Downs JR, Clearfield M, Weis S, et al. Primary prevention of acute coronary events with lovastatin in men and women with average cholesterol levels: results of AFCAPS/ TexCAPS. Air Force/Texas Coronary Atherosclerosis Prevention Study. JAMA 1998;279:1615-22.

19. Stone NJ, Robinson JG, Lichtenstein AH, et al. 2013 ACC/AHA guideline on the treatment of blood cholesterol to reduce atherosclerotic cardiovascular risk in adults: a report of the American College of Cardiology/American Heart Association Task Force on Practice Guidelines. Circulation 2014;129:S1-45.

20. Takemoto M, Liao JK. Pleiotropic effects of 3-hydroxy3-methylglutaryl coenzyme a reductase inhibitors. Arterioscler Thromb Vasc Biol. 2001;21:1712-9.

21. Liao JK. Effects of statins on 3-hydroxy-3-methylglutaryl coenzyme a reductase inhibition beyond low-density lipoprotein cholesterol. Am J Cardiol 2005;96:24F-33F.

22. Zhou Q, Liao JK. Pleiotropic effects of statins. - Basic research and clinical perspectives. Circ J 2010;74:818-26.

23. Fukumoto Y, Libby P, Rabkin E, et al. Statins alter smooth muscle cell accumulation and collagen content in established atheroma of watanabe heritable hyperlipidemic rabbits. Circulation 2001;103:993-9.

24. Baigent C, Keech A, Kearney PM, et al. Efficacy and safety of cholesterol-lowering treatment: prospective metaanalysis of data from 90,056 participants in 14 randomised trials of statins. Lancet 2005;366:1267-78.

25. Colhoun HM, Betteridge DJ, Durrington PN, et al. 
Primary prevention of cardiovascular disease with atorvastatin in type 2 diabetes in the Collaborative Atorvastatin Diabetes Study (CARDS): multicentre randomised placebo-controlled trial. Lancet 2004;364:685-96.

26. Stamler J, Vaccaro O, Neaton JD, et al. Diabetes, other risk factors, and 12-yr cardiovascular mortality for men screened in the Multiple Risk Factor Intervention Trial. Diabetes Care 1993;16:434-44.

27. Wiviott SD, Cannon CP, Morrow DA, et al. Can lowdensity lipoprotein be too low? The safety and efficacy of achieving very low low-density lipoprotein with intensive statin therapy: a PROVE IT-TIMI 22 substudy. J Am Coll Cardiol 2005;46:1411-6.

28. Nissen SE, Nicholls SJ, Sipahi I, et al. Effect of very high-intensity statin therapy on regression of coronary atherosclerosis: the ASTEROID trial. JAMA 2006;295:1556-65.

29. Okazaki S, Yokoyama T, Miyauchi K, et al. Early statin treatment in patients with acute coronary syndrome: demonstration of the beneficial effect on atherosclerotic lesions by serial volumetric intravascular ultrasound analysis during half a year after coronary event: the ESTABLISH Study. Circulation 2004;110:1061-8.

30. Stone GW, Maehara A, Lansky AJ, et al. A prospective natural-history study of coronary atherosclerosis. N Engl J Med 2011;364:226-35.

31. Calvert PA, Obaid DR, O'Sullivan M, et al. Association between IVUS findings and adverse outcomes in patients with coronary artery disease: the VIVA (VH-IVUS in Vulnerable Atherosclerosis) Study. JACC Cardiovasc Imaging 2011;4:894-901.

32. Nissen SE, Tuzcu EM, Schoenhagen P, et al. Effect of intensive compared with moderate lipid-lowering therapy on progression of coronary atherosclerosis: a randomized controlled trial. JAMA 2004;291:1071-80.

33. Cannon CP, Braunwald E, McCabe CH, et al. Intensive versus moderate lipid lowering with statins after acute coronary syndromes. N Engl J Med 2004;350:1495-504.

34. Nicholls SJ, Ballantyne CM, Barter PJ, et al. Effect of two intensive statin regimens on progression of coronary disease. N Engl J Med 2011;365:2078-87.

35. Takano M, Mizuno K, Yokoyama S, et al. Changes in coronary plaque color and morphology by lipid-lowering therapy with atorvastatin: serial evaluation by coronary angioscopy. J Am Coll Cardiol 2003;42:680-6.

36. Uchida Y, Uchida Y, Kawai S, et al. Detection of vulnerable coronary plaques by color fluorescent angioscopy. JACC
Cardiovasc Imaging 2010;3:398-408.

37. Taguchi I, Oda K, Yoneda S, et al. Evaluation of serial changes in tissue characteristics during statin-induced plaque regression using virtual histology-intravascular ultrasound studies. Am J Cardiol 2013;111:1246-52.

38. Egede R, Jensen LO, Hansen HS, et al. Influence of highdose lipid lowering treatment compared to low-dose lipid lowering treatment on plaque composition assessed by intravascular ultrasound virtual histology in patients with ST-segment elevation acute myocardial infarction: the VIRHISTAMI trial. EuroIntervention 2013;8:1182-9.

39. Nasu K, Tsuchikane E, Katoh O, et al. Effect of fluvastatin on progression of coronary atherosclerotic plaque evaluated by virtual histology intravascular ultrasound. JACC Cardiovasc Interv 2009;2:689-96.

40. Nozue T, Yamamoto S, Tohyama S, et al. Statin treatment for coronary artery plaque composition based on intravascular ultrasound radiofrequency data analysis. Am Heart J 2012;163:191-9.e1.

41. Puri R, Nicholls SJ, Shao M, et al. Impact of statins on serial coronary calcification during atheroma progression and regression. J Am Coll Cardiol 2015;65:1273-82.

42. Hattori K, Ozaki Y, Ismail TF, et al. Impact of statin therapy on plaque characteristics as assessed by serial OCT, grayscale and integrated backscatter-IVUS. JACC Cardiovasc Imaging 2012;5:169-77.

43. Takarada S, Imanishi T, Kubo T, et al. Effect of statin therapy on coronary fibrous-cap thickness in patients with acute coronary syndrome: assessment by optical coherence tomography study. Atherosclerosis 2009;202:491-7.

44. Komukai K, Kubo T, Kitabata H, et al. Effect of atorvastatin therapy on fibrous cap thickness in coronary atherosclerotic plaque as assessed by optical coherence tomography: the EASY-FIT study. J Am Coll Cardiol 2014;64:2207-17.

45. Sudhop T, Lutjohann D, Kodal A, et al. Inhibition of intestinal cholesterol absorption by ezetimibe in humans. Circulation 2002;106:1943-8.

46. Cannon CP, Blazing MA, Giugliano RP, et al. Ezetimibe Added to Statin Therapy after Acute Coronary Syndromes. N Engl J Med 2015;372:2387-97.

47. Ballantyne CM, Blazing MA, King TR, et al. Efficacy and safety of ezetimibe co-administered with simvastatin compared with atorvastatin in adults with hypercholesterolemia. Am J Cardiol 2004;93:1487-94.

48. Morrone D, Weintraub WS, Toth PP, et al. Lipid-altering efficacy of ezetimibe plus statin and statin monotherapy and identification of factors associated with treatment 
response: a pooled analysis of over 21,000 subjects from 27 clinical trials. Atherosclerosis 2012;223:251-61.

49. Habara M, Nasu K, Terashima M, et al. Impact on optical coherence tomographic coronary findings of fluvastatin alone versus fluvastatin + ezetimibe. Am J Cardiol 2014;113:580-7.

50. Chapman MJ, Redfern JS, McGovern ME, et al. Niacin and fibrates in atherogenic dyslipidemia: pharmacotherapy to reduce cardiovascular risk. Pharmacol Ther 2010;126:314-45.

51. Miller NE, Thelle DS, Forde OH, et al. The Tromso heart-study. High-density lipoprotein and coronary heart-disease: a prospective case-control study. Lancet 1977;1:965-8.

52. Castelli WP, Garrison RJ, Wilson PW, et al. Incidence of coronary heart disease and lipoprotein cholesterol levels. The Framingham Study. JAMA 1986;256:2835-8.

53. Gordon DJ, Rifkind BM. High-density lipoprotein-the clinical implications of recent studies. N Engl J Med 1989;321:1311-6.

54. Franceschini G. Epidemiologic evidence for high-density lipoprotein cholesterol as a risk factor for coronary artery disease. Am J Cardiol 2001;88:9N-13N.

55. Castelli WP. Cholesterol and lipids in the risk of coronary artery disease--the Framingham Heart Study. Can J Cardiol 1988;4 Suppl A:5A-10A.

56. Barter P, Gotto AM, LaRosa JC, et al. HDL cholesterol, very low levels of LDL cholesterol, and cardiovascular events. N Engl J Med 2007;357:1301-10.

57. Jafri H, Alsheikh-Ali AA, Karas RH. Meta-analysis: statin therapy does not alter the association between low levels of high-density lipoprotein cholesterol and increased cardiovascular risk. Ann Intern Med 2010;153:800-8.

58. von Eckardstein A, Nofer JR, Assmann G. High density lipoproteins and arteriosclerosis. Role of cholesterol efflux and reverse cholesterol transport. Arterioscler Thromb Vasc Biol 2001;21:13-27.

59. Nicholls SJ, Tuzcu EM, Sipahi I, et al. Statins, highdensity lipoprotein cholesterol, and regression of coronary atherosclerosis. JAMA 2007;297:499-508.

60. Ozaki Y, Tanaka A, Komukai K, et al. High-density lipoprotein cholesterol level is associated with fibrous cap thickness in acute coronary syndrome. Circ J 2013;77:2982-9.

61. Boden WE, Probstfield JL, Anderson T, et al. Niacin in patients with low HDL cholesterol levels receiving intensive statin therapy. N Engl J Med 2011;365:2255-67.

62. Schwartz GG, Olsson AG, Abt M, et al. Effects of dalcetrapib in patients with a recent acute coronary syndrome. N Engl J Med 2012;367:2089-99.

63. AIM-HIGH Investigators, Boden WE, Probstfield JL, et al. Niacin in patients with low HDL cholesterol levels receiving intensive statin therapy. $\mathrm{N}$ Engl J Med 2011;365:2255-67.

64. Schwartz GG, Olsson AG, Abt M, et al. Effects of dalcetrapib in patients with a recent acute coronary syndrome. N Engl J Med 2012;367:2089-99.

65. Khera AV, Cuchel M, de la Llera-Moya M, et al. Cholesterol efflux capacity, high-density lipoprotein function, and atherosclerosis. N Engl J Med 2011;364:127-35.

66. Rohatgi A, Khera A, Berry JD, et al. HDL cholesterol efflux capacity and incident cardiovascular events. N Engl J Med 2014;371:2383-93.

67. Shah PK, Yano J, Reyes O, et al. High-dose recombinant apolipoprotein A-I (milano) mobilizes tissue cholesterol and rapidly reduces plaque lipid and macrophage content in apolipoprotein e-deficient mice. Potential implications for acute plaque stabilization. Circulation 2001;103:3047-50.

68. Tardy C, Goffinet M, Boubekeur N, et al. CER-001, a HDL-mimetic, stimulates the reverse lipid transport and atherosclerosis regression in high cholesterol dietfed LDL-receptor deficient mice. Atherosclerosis 2014;232:110-8.

69. Iwata A, Miura S, Zhang B, et al. Antiatherogenic effects of newly developed apolipoprotein A-I mimetic peptide/ phospholipid complexes against aortic plaque burden in Watanabe-heritable hyperlipidemic rabbits. Atherosclerosis 2011;218:300-7.

70. Cho KH. A reconstituted high density lipoprotein containing the V156E mutant of apolipoprotein A-I exhibits anti-atherosclerotic activity in Apo-E deficient mice. J Atheroscler Thromb 2009;16:217-29.

71. Chen Z, O'Neill EA, Meurer RD, et al. Reconstituted HDL elicits marked changes in plasma lipids following single-dose injection in C57Bl/6 mice. J Cardiovasc Pharmacol Ther 2012;17:315-23.

72. Sacks FM, Rudel LL, Conner A, et al. Selective delipidation of plasma HDL enhances reverse cholesterol transport in vivo. J Lipid Res 2009;50:894-907.

73. Rayner KJ, Sheedy FJ, Esau CC, et al. Antagonism of miR-33 in mice promotes reverse cholesterol transport and regression of atherosclerosis. J Clin Invest 2011;121:2921-31.

74. Garber DW, Datta G, Chaddha M, et al. A new synthetic 
class A amphipathic peptide analogue protects mice from diet-induced atherosclerosis. J Lipid Res 2001;42:545-52.

75. Uehara Y, Ando S, Yahiro E, et al. FAMP, a novel apoA-I mimetic peptide, suppresses aortic plaque formation through promotion of biological HDL function in ApoEdeficient mice. J Am Heart Assoc 2013;2:e000048.

76. Nissen SE, Tsunoda T, Tuzcu EM, et al. Effect of recombinant ApoA-I Milano on coronary atherosclerosis in patients with acute coronary syndromes: a randomized controlled trial. JAMA 2003;290:2292-300.

77. Nicholls SJ, Tuzcu EM, Sipahi I, et al. Relationship between atheroma regression and change in lumen size after infusion of apolipoprotein A-I Milano. J Am Coll Cardiol 2006;47:992-7.

78. Tardif JC, Gregoire J, L'Allier PL, et al. Effects of reconstituted high-density lipoprotein infusions on coronary atherosclerosis: a randomized controlled trial. JAMA 2007;297:1675-82.

79. Sambola A, Fuster V, Badimon JJ. Role of coronary risk factors in blood thrombogenicity and acute coronary syndromes. Rev Esp Cardiol 2003;56:1001-9.

80. Kannel WB, McGee DL. Diabetes and cardiovascular risk factors: the Framingham study. Circulation 1979;59:8-13.

81. Kuulasmaa K, Tunstall-Pedoe H, Dobson A, et al. Estimation of contribution of changes in classic risk factors to trends in coronary-event rates across the $\mathrm{WHO}$ MONICA Project populations. Lancet 2000;355:675-87.

82. Zuanetti G, Latini R, Maggioni AP, et al. Influence of diabetes on mortality in acute myocardial infarction: data from the GISSI-2 study. J Am Coll Cardiol 1993;22:1788-94.

83. Mak KH, Moliterno DJ, Granger CB, et al. Influence of diabetes mellitus on clinical outcome in the thrombolytic era of acute myocardial infarction. GUSTO-I Investigators. Global Utilization of Streptokinase and Tissue Plasminogen Activator for Occluded Coronary Arteries. J Am Coll Cardiol 1997;30:171-9.

84. Almdal T, Scharling H, Jensen JS, et al. The independent effect of type 2 diabetes mellitus on ischemic heart disease, stroke, and death: a population-based study of 13,000 men and women with 20 years of follow-up. Arch Intern Med 2004;164:1422-6.

85. Nicholls SJ, Tuzcu EM, Kalidindi S, et al. Effect of diabetes on progression of coronary atherosclerosis and arterial remodeling: a pooled analysis of 5 intravascular ultrasound trials. J Am Coll Cardiol 2008;52:255-62.

86. Moreno PR, Murcia AM, Palacios IF, et al. Coronary composition and macrophage infiltration in atherectomy specimens from patients with diabetes mellitus. Circulation 2000;102:2180-4.

87. Nielson C, Lange T, Hadjokas N. Blood glucose and coronary artery disease in nondiabetic patients. Diabetes Care 2006;29:998-1001.

88. Garg N, Moorthy N, Kapoor A, et al. Hemoglobin A (1c) in nondiabetic patients: an independent predictor of coronary artery disease and its severity. Mayo Clin Proc 2014;89:908-16.

89. Karrowni W, Li Y, Jones PG, et al. Insulin resistance is associated with significant clinical atherosclerosis in nondiabetic patients with acute myocardial infarction. Arterioscler Thromb Vasc Biol 2013;33:2245-51.

90. Bornfeldt KE, Tabas I. Insulin resistance, hyperglycemia, and atherosclerosis. Cell Metab 2011;14:575-85.

91. Srinivasan MP, Kamath PK, Manjrekar PA, et al. Correlation of severity of coronary artery disease with insulin resistance. N Am J Med Sci 2013;5:611-4.

92. Sung KC, Wild SH, Kwag HJ, et al. Fatty liver, insulin resistance, and features of metabolic syndrome: relationships with coronary artery calcium in 10,153 people. Diabetes Care 2012;35:2359-64.

93. Kim SH, Moon JY, Lim YM, et al. Association of insulin resistance and coronary artery remodeling: an intravascular ultrasound study. Cardiovasc Diabetol 2015;14:74.

94. Beckman JA, Goldfine AB, Gordon MB, et al. Oral antioxidant therapy improves endothelial function in Type 1 but not Type 2 diabetes mellitus. Am J Physiol Heart Circ Physiol 2003;285:H2392-8.

95. Schofield I, Malik R, Izzard A, et al. Vascular structural and functional changes in type 2 diabetes mellitus: evidence for the roles of abnormal myogenic responsiveness and dyslipidemia. Circulation 2002;106:3037-43.

96. Tomiyama H, Kushiro T, Okazaki R, et al. Influences of increased oxidative stress on endothelial function, platelets function, and fibrinolysis in hypertension associated with glucose intolerance. Hypertens Res 2003;26:295-300.

97. Paneni F, Costantino S, Cosentino F. Role of oxidative stress in endothelial insulin resistance. World J Diabetes 2015;6:326-32.

98. Effect of intensive blood-glucose control with metformin on complications in overweight patients with type 2 diabetes (UKPDS 34). UK Prospective Diabetes Study (UKPDS) Group. Lancet 1998;352:854-65.

99. Forouzandeh F, Salazar G, Patrushev N, et al. Metformin beyond diabetes: pleiotropic benefits of metformin in attenuation of atherosclerosis. J Am Heart Assoc 2014;3:e001202. 
100.Johnson JA, Simpson SH, Toth EL, Majumdar SR. Reduced cardiovascular morbidity and mortality associated with metformin use in subjects with Type 2 diabetes. Diabet Med 2005;22:497-502.

101.Lexis CP, van der Horst IC. Metformin for cardiovascular disease: promise still unproven. Lancet Diabetes Endocrinol 2014;2:94-5.

102.Kung J, Henry RR. Thiazolidinedione safety. Expert Opin Drug Saf 2012;11:565-79.

103. Cariou B, Charbonnel B, Staels B. Thiazolidinediones and PPARgamma agonists: time for a reassessment. Trends Endocrinol Metab 2012;23:205-15.

104. Dormandy JA, Charbonnel B, Eckland DJ, et al. Secondary prevention of macrovascular events in patients with type 2 diabetes in the PROactive Study (PROspective pioglitAzone Clinical Trial In macroVascular Events): a randomised controlled trial. Lancet 2005;366:1279-89.

105. Nissen SE, Nicholls SJ, Wolski K, et al. Comparison of pioglitazone vs glimepiride on progression of coronary atherosclerosis in patients with type 2 diabetes: the PERISCOPE randomized controlled trial. JAMA 2008;299:1561-73.

106. Goldin A, Beckman JA, Schmidt AM, et al. Advanced glycation end products: sparking the development of diabetic vascular injury. Circulation 2006;114:597-605.

107. Brownlee M. Biochemistry and molecular cell biology of diabetic complications. Nature 2001;414:813-20.

108. Beckman JA, Creager MA, Libby P. Diabetes and atherosclerosis: epidemiology, pathophysiology, and management. JAMA 2002;287:2570-81.

109. Schneider DJ, Sobel BE. Augmentation of synthesis of plasminogen activator inhibitor type 1 by insulin and insulin-like growth factor type I: implications for vascular disease in hyperinsulinemic states. Proc Natl Acad Sci U S A 1991;88:9959-63.

110.DECODE Study Group, the European Diabetes Epidemiology Group. Glucose tolerance and cardiovascular mortality: comparison of fasting and 2-hour diagnostic criteria. Arch Intern Med 2001;161:397-405.

111. Tominaga M, Eguchi H, Manaka H, et al. Impaired glucose tolerance is a risk factor for cardiovascular disease, but not impaired fasting glucose. The Funagata Diabetes Study. Diabetes Care 1999;22:920-4.

112. Ceriello A, Esposito K, Piconi L, et al. Glucose "peak" and glucose "spike": Impact on endothelial function and oxidative stress. Diabetes Res Clin Pract 2008;82:262-7.

113. Chiasson JL, Josse RG, Gomis R, et al. Acarbose treatment and the risk of cardiovascular disease and hypertension in patients with impaired glucose tolerance: the STOP-

NIDDM trial. JAMA 2003;290:486-94.

114. Hanefeld M, Cagatay M, Petrowitsch T, et al. Acarbose reduces the risk for myocardial infarction in type 2 diabetic patients: meta-analysis of seven long-term studies. Eur Heart J 2004;25:10-6.

115. Brown A, Reynolds LR, Bruemmer D. Intensive glycemic control and cardiovascular disease: an update. Nat Rev Cardiol 2010;7:369-75.

116. Gerstein HC, Miller ME, Genuth S, et al. Long-term effects of intensive glucose lowering on cardiovascular outcomes. N Engl J Med 2011;364:818-28.

117.Hemmingsen B, Lund SS, Gluud C, et al. Intensive glycaemic control for patients with type 2 diabetes: systematic review with meta-analysis and trial sequential analysis of randomised clinical trials. BMJ 2011;343:d6898.

118. Dandona P, Chaudhuri A, Dhindsa S. Proinflammatory and prothrombotic effects of hypoglycemia. Diabetes Care 2010;33:1686-7.

119. Wang J, Alexanian A, Ying R, et al. Acute exposure to low glucose rapidly induces endothelial dysfunction and mitochondrial oxidative stress: role for AMP kinase. Arterioscler Thromb Vasc Biol 2012;32:712-20.

120. Monnier L, Mas E, Ginet C, et al. Activation of oxidative stress by acute glucose fluctuations compared with sustained chronic hyperglycemia in patients with type 2 diabetes. JAMA 2006;295:1681-7.

121. Nalysnyk L, Hernandez-Medina M, Krishnarajah G. Glycaemic variability and complications in patients with diabetes mellitus: evidence from a systematic review of the literature. Diabetes Obes Metab 2010;12:288-98.

122. Wang X, Zhao X, Dorje T, et al. Glycemic variability predicts cardiovascular complications in acute myocardial infarction patients with type 2 diabetes mellitus. Int J Cardiol 2014;172:498-500.

123. Teraguchi I, Imanishi T, Ozaki Y, et al. Impact of glucose fluctuation and monocyte subsets on coronary plaque rupture. Nutr Metab Cardiovasc Dis 2014;24:309-14.

124.Kuroda M, Shinke T, Sakaguchi K, et al. Association between daily glucose fluctuation and coronary plaque properties in patients receiving adequate lipid-lowering therapy assessed by continuous glucose monitoring and optical coherence tomography. Cardiovasc Diabetol 2015;14:78.

125. Neaton JD, Wentworth D. Serum cholesterol, blood pressure, cigarette smoking, and death from coronary heart disease. Overall findings and differences by age for 316,099 white men. Multiple Risk Factor Intervention 
Trial Research Group. Arch Intern Med 1992;152:56-64. 126.van den Hoogen PC, Feskens EJ, Nagelkerke NJ, et al. The relation between blood pressure and mortality due to coronary heart disease among men in different parts of the world. Seven Countries Study Research Group. N Engl J Med 2000;342:1-8.

127. Chobanian AV, Bakris GL, Black HR, et al. Seventh report of the Joint National Committee on Prevention, Detection, Evaluation, and Treatment of High Blood Pressure. Hypertension 2003;42:1206-52.

128.McGill HC Jr, McMahan CA, Zieske AW, et al. Associations of coronary heart disease risk factors with the intermediate lesion of atherosclerosis in youth. The Pathobiological Determinants of Atherosclerosis in Youth (PDAY) Research Group. Arterioscler Thromb Vasc Biol 2000;20:1998-2004.

129. Wissler RW. An overview of the quantitative influence of several risk factors on progression of atherosclerosis in young people in the United States. Pathobiological Determinants of Atherosclerosis in Youth (PDAY) Research Group. Am J Med Sci 1995;310 Suppl 1:S29-36.

130.Law MR, Morris JK, Wald NJ. Use of blood pressure lowering drugs in the prevention of cardiovascular disease: meta-analysis of 147 randomised trials in the context of expectations from prospective epidemiological studies. BMJ 2009;338:b1665.

131.Lv J, Neal B, Ehteshami P, et al. Effects of intensive blood pressure lowering on cardiovascular and renal outcomes: a systematic review and meta-analysis. PLoS Med 2012;9:e1001293.

132. Emdin CA, Rahimi K, Neal B, et al. Blood pressure lowering in type 2 diabetes: a systematic review and metaanalysis. JAMA 2015;313:603-15.

133.Lonn EM, Yusuf S, Jha P, et al. Emerging role of angiotensin-converting enzyme inhibitors in cardiac and vascular protection. Circulation 1994;90:2056-69.

134. Yusuf S, Sleight P, Pogue J, et al. Effects of an angiotensinconverting-enzyme inhibitor, ramipril, on cardiovascular events in high-risk patients. The Heart Outcomes Prevention Evaluation Study Investigators. N Engl J Med 2000;342:145-53.

135. Fox KM. Efficacy of perindopril in reduction of cardiovascular events among patients with stable coronary artery disease: randomised, double-blind, placebocontrolled, multicentre trial (the EUROPA study). Lancet 2003;362:782-8.

136. Mogielnicki A, Chabielska E, Pawlak R, et al. Angiotensin II enhances thrombosis development in renovascular hypertensive rats. Thromb Haemost 2005;93:1069-76.

137. Bauriedel G, Skowasch D, Schneider M, et al. Antiplatelet effects of angiotensin-converting enzyme inhibitors compared with aspirin and clopidogrel: a pilot study with whole-blood aggregometry. Am Heart J 2003;145:343-8.

138. Iwanami J, Mogi M, Iwai M, et al. Inhibition of the reninangiotensin system and target organ protection. Hypertens Res 2009;32:229-37.

139.Holecki M, Szewieczek J, Chudek J. Effects of angiotensinconverting enzyme inhibitors beyond lowering blood pressure--are they important for doctors? Pharmacol Rep 2011;63:740-51.

140. Hotchi J, Hoshiga M, Takeda Y, et al. Plaque-stabilizing effect of angiotensin-converting enzyme inhibitor and/or angiotensin receptor blocker in a rabbit plaque model. J Atheroscler Thromb 2013;20:257-66.

141. Waseda K, Ozaki Y, Takashima H, et al. Impact of angiotensin II receptor blockers on the progression and regression of coronary atherosclerosis: an intravascular ultrasound study. Circ J 2006;70:1111-5.

142. Hirohata A, Yamamoto K, Miyoshi T, et al. Impact of olmesartan on progression of coronary atherosclerosis a serial volumetric intravascular ultrasound analysis from the OLIVUS (impact of OLmesarten on progression of coronary atherosclerosis: evaluation by intravascular ultrasound) trial. J Am Coll Cardiol 2010;5 5:976-82 .

143. Ishii H, Kobayashi M, Kurebayashi N, et al. Impact of angiotensin II receptor blocker therapy (olmesartan or valsartan) on coronary atherosclerotic plaque volume measured by intravascular ultrasound in patients with stable angina pectoris. Am J Cardiol 2013;112:363-8.

144. Cipollone F, Fazia ML, Mezzetti A. Role of angiotensin II receptor blockers in atherosclerotic plaque stability. Expert Opin Pharmacother 2006;7:277-85.

145. de Cavanagh EM, Piotrkowski B, Fraga CG. Concerted action of the renin-angiotensin system, mitochondria, and antioxidant defenses in aging. Mol Aspects Med 2004;25:27-36.

146. Min LJ, Mogi M, Iwanami J, et al. Cross-talk between aldosterone and angiotensin II in vascular smooth muscle cell senescence. Cardiovasc Res 2007;76:506-16.

147. Basso N, Paglia N, Stella I, et al. Protective effect of the inhibition of the renin-angiotensin system on aging. Regul Pept 2005;128:247-52.

148. Neal B, MacMahon S, Chapman N. Effects of ACE inhibitors, calcium antagonists, and other blood-pressurelowering drugs: results of prospectively designed overviews of randomised trials. Blood Pressure Lowering Treatment 
Trialists' Collaboration. Lancet 2000;356:1955-64.

149.Pitt B, Byington RP, Furberg CD, et al. Effect of amlodipine on the progression of atherosclerosis and the occurrence of clinical events. PREVENT Investigators. Circulation 2000;102:1503-10.

150.Jørgensen B, Simonsen S, Endresen K, et al. Restenosis and clinical outcome in patients treated with amlodipine after angioplasty: results from the Coronary AngioPlasty Amlodipine REStenosis Study (CAPARES). J Am Coll Cardiol 2000;35:592-9.

151. Chen L, Haught WH, Yang B, et al. Preservation of endogenous antioxidant activity and inhibition of lipid peroxidation as common mechanisms of antiatherosclerotic effects of vitamin E, lovastatin and amlodipine. J Am Coll Cardiol 1997;30:569-75.

152.Mason RP, Walter MF, Trumbore MW, et al. Membrane antioxidant effects of the charged dihydropyridine calcium antagonist amlodipine. J Mol Cell Cardiol 1999;31:275-81.

153. Yoshii T, Iwai M, Li Z, et al. Regression of atherosclerosis by amlodipine via anti-inflammatory and anti-oxidative stress actions. Hypertens Res 2006;29:457-66.

154.Prichard BN, Gillam PM. USE OF PROPRANOLOL (INDERAL) IN TREATMENT OF HYPERTENSION. Br Med J 1964;2:725-7.

155.Feuerstein GZ, Ruffolo RR Jr. Carvedilol, a novel vasodilating beta-blocker with the potential for cardiovascular organ protection. Eur Heart J 1996;17 Suppl B:24-9.

156.Bøttcher M, Falk E. Pathology of the coronary arteries in smokers and non-smokers. J Cardiovasc Risk 1999;6:299-302.

157. Teo KK, Ounpuu S, Hawken S, et al. Tobacco use and risk of myocardial infarction in 52 countries in the INTERHEART study: a case-control study. Lancet 2006;368:647-58.

158. Wissler RW. New insights into the pathogenesis of atherosclerosis as revealed by PDAY. Pathobiological Determinants of Atherosclerosis in Youth. Atherosclerosis 1994;108 Suppl:S3-20.

159. Burke AP, Farb A, Malcom GT, et al. Effect of risk factors on the mechanism of acute thrombosis and sudden coronary death in women. Circulation 1998;97:2110-6.

160. Barua RS, Ambrose JA. Mechanisms of coronary thrombosis in cigarette smoke exposure. Arterioscler Thromb Vasc Biol 2013;33:1460-7.

161. Raveendran M, Senthil D, Utama B, et al. Cigarette suppresses the expression of $\mathrm{P} 4 \mathrm{Halpha}$ and vascular collagen production. Biochem Biophys Res Commun 2004;323:592-8.

162.Perlstein TS, Lee RT. Smoking, metalloproteinases, and vascular disease. Arterioscler Thromb Vasc Biol 2006;26:250-6.

163. Sivaraman SK, Zachariah G, Annamala P. Effect of Smoking on Metalloproteinases (MMPs) Activity in Patients with Acute Myocardial Infarction (AMI). J Clin Diagn Res 2014;8:27-30.

164.Mjøs OD. Lipid effects of smoking. Am Heart J 1988;115:272-5.

165. Maeda K, Noguchi Y, Fukui T. The effects of cessation from cigarette smoking on the lipid and lipoprotein profiles: a meta-analysis. Prev Med 2003;37:283-90.

166. Takata K, Imaizumi S, Kawachi E, et al. Impact of cigarette smoking cessation on high-density lipoprotein functionality. Circ J 2014;78:2955-62.

167.Libby P, Ridker PM, Hansson GK. Inflammation in atherosclerosis: from pathophysiology to practice. J Am Coll Cardiol 2009;54:2129-38.

168. Puri R, Nissen SE, Libby P, et al. C-reactive protein, but not low-density lipoprotein cholesterol levels, associate with coronary atheroma regression and cardiovascular events after maximally intensive statin therapy. Circulation 2013;128:2395-403.

169. Ridker PM, Danielson E, Fonseca FA, et al. Rosuvastatin to prevent vascular events in men and women with elevated C-reactive protein. N Engl J Med 2008;359:2195-207.

170. Robertson AK, Hansson GK. T cells in atherogenesis: for better or for worse? Arterioscler Thromb Vasc Biol 2006;26:2421-32.

171.Mosmann TR, Cherwinski H, Bond MW, et al. Two types of murine helper T cell clone. I. Definition according to profiles of lymphokine activities and secreted proteins. J Immunol 1986;136:2348-57.

172.Miao J, Zhang K, Lv M, et al. Circulating Th17 and Th1 cells expressing CD161 are associated with disease activity in rheumatoid arthritis. Scand J Rheumatol 2014;43:194-201.

173. Atkinson MA, Eisenbarth GS. Type 1 diabetes: new perspectives on disease pathogenesis and treatment. Lancet 2001;358:221-9.

174.Xia CQ, Peng R, Chernatynskaya AV, et al. Increased IFN-alpha-producing plasmacytoid dendritic cells (pDCs) in human Th1-mediated type 1 diabetes: pDCs augment Th1 responses through IFN-alpha production. J Immunol 2014;193:1024-34. 
175.Lu Y, Sakamaki S, Kuroda H, et al. Prevention of lethal acute graft-versus-host disease in mice by oral administration of T helper 1 inhibitor, TAK-603. Blood 2001;97:1123-30.

176. Fernandes JL, Mamoni RL, Orford JL, et al. Increased Th1 activity in patients with coronary artery disease. Cytokine 2004;26:131-7.

177. Wick G, Knoflach M, Xu Q. Autoimmune and inflammatory mechanisms in atherosclerosis. Annu Rev Immunol 2004;22:361-403.

178. Stemme S, Faber B, Holm J, et al. T lymphocytes from human atherosclerotic plaques recognize oxidized low density lipoprotein. Proc Natl Acad Sci U S A 1995;92:3893-7.

179. Ketelhuth DF, Hansson GK. Cellular immunity, lowdensity lipoprotein and atherosclerosis: break of tolerance in the artery wall. Thromb Haemost 2011;106:779-86.

180. Mallat Z, Taleb S, Ait-Oufella H, et al. The role of adaptive $\mathrm{T}$ cell immunity in atherosclerosis. J Lipid Res 2009;50 Suppl:S364-9.

181. Matsuura E, Atzeni F, Sarzi-Puttini P, et al. Is atherosclerosis an autoimmune disease? BMC Med 2014;12:47.

182. Chen W, Wahl SM. TGF-beta: the missing link in $\mathrm{CD} 4+\mathrm{CD} 25+$ regulatory $\mathrm{T}$ cell-mediated immunosuppression. Cytokine Growth Factor Rev 2003;14:85-9.

183. Pandiyan $\mathrm{P}$, Zheng L, Ishihara S, et al. CD4+CD25+Foxp3+ regulatory $\mathrm{T}$ cells induce cytokine deprivation-mediated apoptosis of effector CD4+ T cells. Nat Immunol 2007;8:1353-62.

184. Wing K, Onishi Y, Prieto-Martin P, et al. CTLA-4 control over Foxp3 + regulatory $T$ cell function. Science 2008;322:271-5

185.von Boehmer H. Mechanisms of suppression by suppressor T cells. Nat Immunol 2005;6:338-44.

186. George J. Mechanisms of disease: the evolving role of regulatory $T$ cells in atherosclerosis. Nat Clin Pract Cardiovasc Med 2008;5:531-40.

187. Olson NC, Doyle MF, Jenny NS, et al. Decreased naive and increased memory CD4 (+) T cells are associated with subclinical atherosclerosis: the multi-ethnic study of atherosclerosis. PLoS One 2013;8:e71498.

188. Sasaki N, Yamashita T, Takeda M, Hirata K. Regulatory $\mathrm{T}$ cells in atherogenesis. $\mathrm{J}$ Atheroscler Thromb 2012;19:503-15.

189. George J, Schwartzenberg S, Medvedovsky D, et al. Regulatory T cells and IL-10 levels are reduced in patients with vulnerable coronary plaques. Atherosclerosis 2012;222:519-23.

190.Shimizu K, Mitchell RN, Libby P. Inflammation and cellular immune responses in abdominal aortic aneurysms. Arterioscler Thromb Vasc Biol 2006;26:987-94.

191. Kuperman DA, Huang X, Koth LL, et al. Direct effects of interleukin-13 on epithelial cells cause airway hyperreactivity and mucus overproduction in asthma. Nat Med 2002;8:885-9.

192. Coffman RL, Seymour BW, Hudak S, et al. Antibody to interleukin-5 inhibits helminth-induced eosinophilia in mice. Science 1989;245:308-10.

193. Binder CJ, Hartvigsen K, Chang MK, et al. IL-5 links adaptive and natural immunity specific for epitopes of oxidized LDL and protects from atherosclerosis. J Clin Invest 2004;114:427-37.

194. Cardilo-Reis L, Gruber S, Schreier SM, et al. Interleukin-13 protects from atherosclerosis and modulates plaque composition by skewing the macrophage phenotype. EMBO Mol Med 2012;4:1072-86.

195. Davenport P, Tipping PG. The role of interleukin-4 and interleukin-12 in the progression of atherosclerosis in apolipoprotein E-deficient mice. Am J Pathol 2003;163:1117-25.

196. King VL, Szilvassy SJ, Daugherty A. Interleukin-4 deficiency decreases atherosclerotic lesion formation in a site-specific manner in female LDL receptor-/- mice. Arterioscler Thromb Vasc Biol 2002;22:456-61.

197. de Boer OJ, van der Meer JJ, Teeling P, et al. Differential expression of interleukin-17 family cytokines in intact and complicated human atherosclerotic plaques. J Pathol 2010;220:499-508.

198. Gong F, Liu Z, Liu J, et al. The paradoxical role of IL-17 in atherosclerosis. Cell Immunol 2015;297:33-9.

199. Madhur MS, Funt SA, Li L, et al. Role of interleukin 17 in inflammation, atherosclerosis, and vascular function in apolipoprotein e-deficient mice. Arterioscler Thromb Vasc Biol 2011;31:1565-72.

200. Chen S, Shimada K, Zhang W, et al. IL-17A is proatherogenic in high-fat diet-induced and Chlamydia pneumoniae infection-accelerated atherosclerosis in mice. J Immunol 2010;185:5619-27.

201. Usui F, Kimura H, Ohshiro T, et al. Interleukin-17 deficiency reduced vascular inflammation and development of atherosclerosis in Western diet-induced apoE-deficient mice. Biochem Biophys Res Commun 2012;420:72-7.

202.Butcher MJ, Gjurich BN, Phillips T, et al. The IL$17 \mathrm{~A} / \mathrm{IL}-17 \mathrm{RA}$ axis plays a proatherogenic role via the 
regulation of aortic myeloid cell recruitment. Circ Res 2012;110:675-87.

203. Shimada K, Park JK, Daida H. T helper 1/T helper 2 balance and HMG-CoA reductase inhibitors in acute coronary syndrome: statins as immunomodulatory agents? Eur Heart J 2006;27:2916-8.

204. Methe H, Brunner S, Wiegand D, et al. Enhanced T-helper-1 lymphocyte activation patterns in acute coronary syndromes. J Am Coll Cardiol 2005;45:1939-45.

205. Cavusoglu E, Marmur JD, Hojjati MR, et al. Plasma interleukin-10 levels and adverse outcomes in acute coronary syndrome. Am J Med 2011;124:724-30.

206.Liuzzo G, Kopecky SL, Frye RL, et al. Perturbation of the T-cell repertoire in patients with unstable angina. Circulation 1999;100:2135-9.

207. Yamashita H, Shimada K, Seki E, et al. Concentrations of interleukins, interferon, and C-reactive protein in stable and unstable angina pectoris. Am J Cardiol 2003;91:133-6.

208. Liuzzo G, Vallejo AN, Kopecky SL, et al. Molecular fingerprint of interferon-gamma signaling in unstable angina. Circulation 2001;103:1509-14.

209. Cheng X, Yu X, Ding YJ, et al. The Th17/Treg imbalance in patients with acute coronary syndrome. Clin Immunol 2008;127:89-97.

210. Potekhina AV, Pylaeva E, Provatorov S, et al. Treg/Th17 balance in stable CAD patients with different stages of

Cite this article as: Takata K, Imaizumi S, Zhang B, Miura SI, Saku K. Stabilization of high-risk plaques. Cardiovasc Diagn Ther 2016;6(4):304-321. doi: 10.21037/cdt.2015.10.03 coronary atherosclerosis. Atherosclerosis 2015;238:17-21.

211.Link A, Ayadhi T, Bohm M, et al. Rapid immunomodulation by rosuvastatin in patients with acute coronary syndrome. Eur Heart J 2006;27:2945-55.

212. Mausner-Fainberg K, Luboshits G, Mor A, et al. The effect of HMG-CoA reductase inhibitors on naturally occurring CD4+CD25+ T cells. Atherosclerosis 2008;197:829-39.

213. Kagami S, Owada T, Kanari H, et al. Protein geranylgeranylation regulates the balance between Th17 cells and Foxp3+ regulatory T cells. Int Immunol 2009;21:679-89.

214. Tousoulis D, Psarros C, Demosthenous M, et al. Innate and adaptive inflammation as a therapeutic target in vascular disease: the emerging role of statins. J Am Coll Cardiol 2014;63:2491-502.

215. Tiniakou I, Drakos E, Sinatkas V, et al. High-density lipoprotein attenuates Th1 and th 17 autoimmune responses by modulating dendritic cell maturation and function. J Immunol 2015;194:4676-87.

216.Ammirati E, Cianflone D, Banfi M, et al. Circulating CD4+CD25hiCD127lo regulatory T-Cell levels do not reflect the extent or severity of carotid and coronary atherosclerosis. Arterioscler Thromb Vasc Biol 2010;30:1832-41. 